\title{
Coastal Processes and Longshore Sediment Transport along Zemmouri Bay, Central East Coast of Algeria
}

Khoudir Mezouar, Romeo Ciortan

\begin{abstract}
The coastline of Zemmouri Bay on the northeast coast of Algeria with about $50 \mathrm{~km}$ of shoreline has been eroding since 1970 . Changes of the sandy shoreline are continuous and occur at diverse spatial and temporal scales. This erosion is a major crisis and it potentially impacts the coastal population and natural environment. In order to understand and predict these morphological changes, an accurate description of sediment transport by waves and currents and shoreline change is important. This paper presents a comprehensive study of wave refraction, current-driven sediment transport and shoreline change. Results show that the study area exhibits a great variety of shoreline evolution trends, with erosion prevailing in the eastern and central sectors and stability or even accretion in the Western area.
\end{abstract}

Keywords - Zemmouri Bay, sediment transport, shoreline, hydrodynamic, coastal process.

\section{INTRODUCTION}

Changes of shoreline position have become, in recent years, one of the major environment problems affecting coastal zones worldwide. Knowledge of shoreline behaviour is important for understanding and mitigating coastal problems. Erosion and accretion of beaches are strongly related to variations in wave intensity, longshore migration of sand waves, and changes in beach and dune sediment budgets. Long-term changes are often difficult to quantify because there are many short-term variations related to mean-water-level variations, storm intensity, which contribute to seasonal beach-profile variations. The sandy coast of Zemmouri, which was left in its natural state until early 1980, has been the subject, in recent decades, of a major regional development program. This program was concretized by the construction of infrastructures (construction of a two port Djinet and Zemmouri, construction of electrical station...). These development operations contributed to economic development of this locality, but they have also destabilized the natural balance of this coastal area, which supports today a high density of infrastructures. This study analyzed shoreline changes for a period of 45 years (19722017), using geospatial techniques, geographic information systems (GIS) and automatic computation (DSAS), of the Zemmouri coast. In this study, several statistical approaches have been used for determining the rates of shoreline changes, including End Point Rates (EPR), Linear Regression Rates (LRR). The model MIKE21 will be used to analyse the hydrodynamic conditions and sediment transport patterns at sandy coast.

ISSN 2392-6139 / ISSN-L 1584-5990 


\section{STUDY AREA}

The study area extends from Cap Djinet in the Est to Cap Matifou in the West covering a total length of $54 \mathrm{~km}$. It lies between $36^{\circ} 53^{\prime} 00^{\prime}-36^{\circ} 48^{\prime} 00^{\prime \prime} \mathrm{N}$ Latitude and $3^{\circ} 13^{\prime} 18^{\prime \prime}-3^{\circ} 43^{\prime} 24^{\prime \prime}$ E Longitude and oriented North (Fig.1).

The climate of Zemmouri Bay is characterized by an irregular Mediterranean regime subhumid to humid weather with two distinct seasons: a cold rainy winter and a hot dry summer. However, the proximity effect to the sea confers to this area a temperate climate, as well as the rainfall and thermic distribution is strongly influenced. Indeed, the summer season ranging from May to October. It is characterized with a moderate temperature of $25{ }^{\circ} \mathrm{C}$ in August. During the winter, February is the coldest month where the temperature could achieve $12{ }^{\circ} \mathrm{C}$. These results are confirmed by statistical analyses of temperature between the years 1996 to 2014 Meteorology National Office (MNO) which were recorded by the closest station to the study area located at Dellys AFIR.

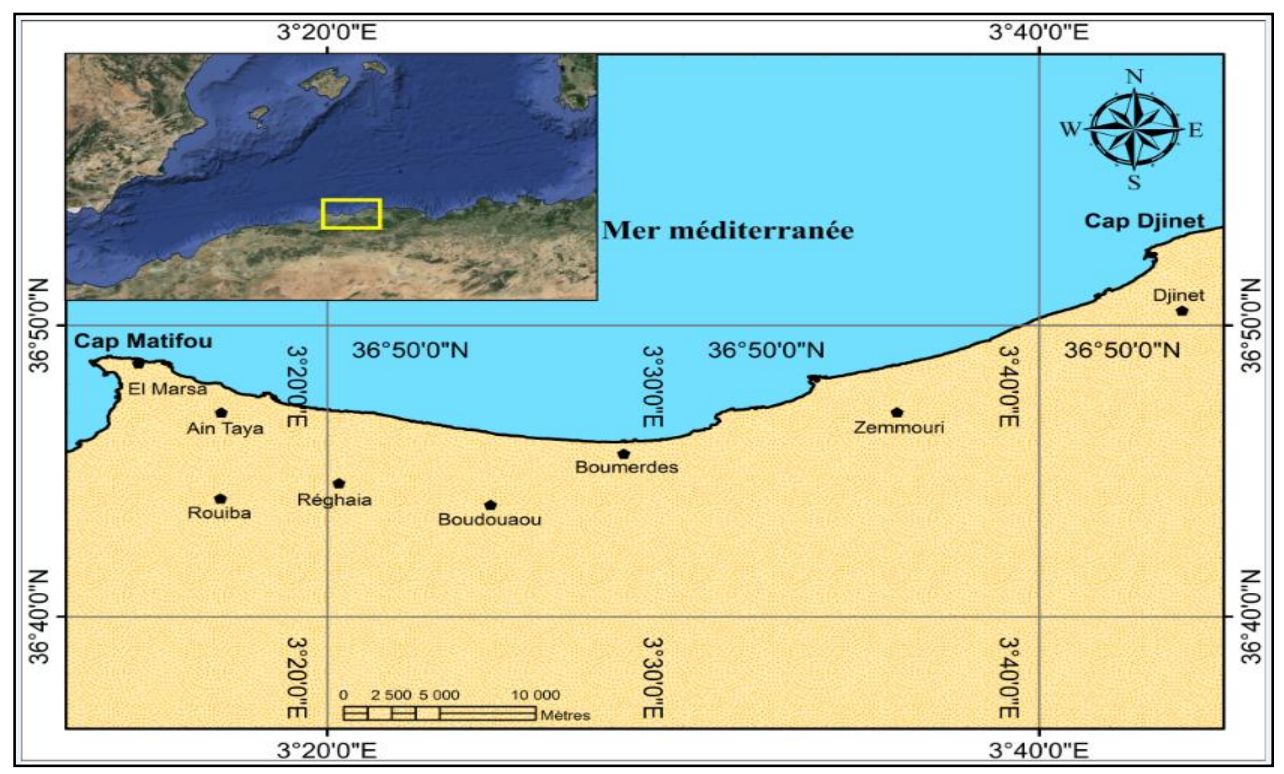

Fig. 1. Zemmouri Bay map location

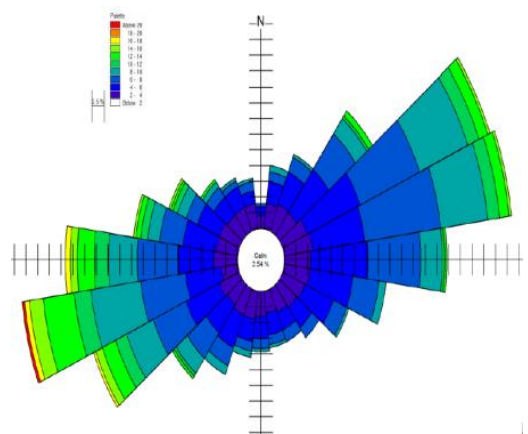

Fig.2. Wind rose (Medatlas 2014)

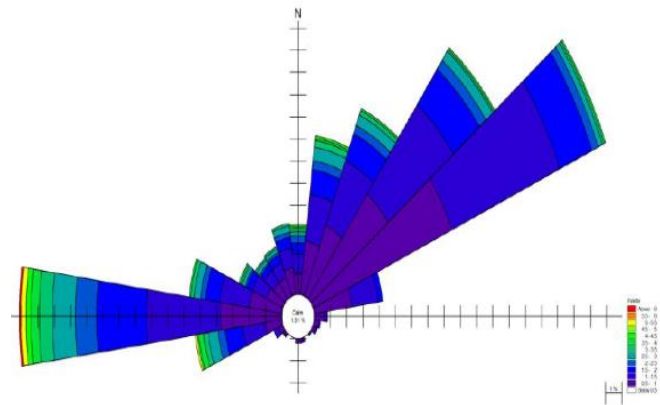

Fig.3. Wave rose (Medatlas 2014) 
At Zemmouri, the wind regime analysis is performed using data of MNO data from 1996 to 2014 (Fig 1). These results show that our study area is characterized by west and northwest winds during the winter season and east and northeast winds during the summer season. Much of the winds issued from these directions have speeds above $8 \mathrm{~m} / \mathrm{s}$. For the third quarter, the prevailing winds came from $\mathrm{E}$ and $\mathrm{NE}$ directions, with low to medium speeds $(1-5 \mathrm{~m} / \mathrm{s})$.

The determination of swell characteristics permits to analyze the coastline evolution on the one part and estimate the sediment transit on the other part. For that, the data used are the observations measurements which were made off in the Algerian coasts with Medatlas Company 1999-2004. Fig 3 shows the occurred monthly frequency of the swells as function of directions. The study area is exposed to dominant waves coming from the North-East and West sectors with respective frequencies of $42 \%$ and $29 \%$. The strong marine agitations with heights exceeding $2.75 \mathrm{~m}$ are observed during the first and fourth quarter are mainly dominant with respective frequencies of 23,18 and $12 \%$, and heights that vary from 0.75 to $1.75 \mathrm{~m}$. The recorded wave's heights vary between 0.25 and $6 \mathrm{~m}$. The period of dominant swells vary between 5.03 and $8.1 \mathrm{~s}$.

\section{MATERIALS AND METHODS}

\subsection{Hydrodynamic modelling}

Three numerical models are used to investigate the sources of hydrodynamic and sediment drift in the Zemmouri coast (MIKE 21 SW, MIKE 21 HD, MIKE 21 ST).

MIKE $21 \mathrm{SW}$ is a third generation spectral wind-wave energy model based on unstructured meshes and considers wave growth, dissipation and non-linear wave interactions. This is used for knowing the variations in wave characteristics by changing various model parameters.

MIKE 21 Flow Model - HD is a modelling system for 2D free surface flows based on flexible mesh approach. MIKE 21 Flow Model is applicable to the simulation of hydraulic and environmental phenomena in lakes, estuaries, bays, coastal areas and seas.

MIKE21 Flow Model - ST describes erosion, transport and deposition of sand under the action of currents and waves or pure current. It is specifically suited for application to coastal engineering problems for studying sediment transport studies of non-cohesive sediments.

\subsection{Historical shoreline analysis}

In this study, the adopted methodology for treatment and extraction of the shoreline position and the construction of the database, in order to determine the net rate of shoreline movement, is that used by several authors (e.g. [5], [4]). The approach following [2]; [3] comprised a three-stage process: (1) aerial photographs and Quick-bird satellite image covering the period 1972 - 2017 were orthorectified using a polynomial geo-rectification method and a reference line, (2) digitization and extraction of the coastline development and estimation of errors, and (3) data analysis to compute shoreline erosion/accretion rates. In this study, corrected aerial photographs at different scales $1 / 10,000,1 / 20,0001 / 25,000$ obtained from different missions $(1972,1980,1993,2003)$ and satellite imaginiry (Quickbird Multispectral) covering the coast of Zemmouri (2017) were used to detect shoreline changes along the coast. The images were imported into ArcGIS 10.3 for analysis and 
projected to real world coordinate Universal Transverse Mercator (UTM) with reference to WGS-84 datum. After shorelines were digitized for the four dates of aerial photography missions, all shorelines are used as the input to the Digital Shoreline Analysis System (DSAS) to calculate the rate of shoreline movement and changes. In our study, the DSAS was carried out in four steps: (1) shoreline preparation, (2) baseline creation, (3) transect generation, and (4) computation of rate of shoreline change. Shorelines changes rate along the Zemmouri Coast were calculated on 900 transects perpendicular to the baseline at intervals of $50 \mathrm{~m}$. The end point of rate calculation (EPR) and the net shoreline movement (NSM), which are the most prevalent methods used by the majority of agencies that use shoreline data to manage coasts [1]. The EPR method consists to compute the rate at each transect by taking the distance in meter between two shoreline positions and dividing it by the time interval expressed in year, that separated between the youngest and oldest shorelines position.

\section{RESULTS AND DISCUSSIONS}

\subsection{Hydrodynamic}

A detailed wind map was prepared for the period of simulations covering the entire area describing the wind velocity component variations as well as mean sea level pressure distribution. An initial water level variation of $0.41 \mathrm{~m}$ was applied as an average value based on the tidal data at the boundaries. An initial level of $0.35 \mathrm{~m}$ was applied across the domain interpolated from the tidal variation at both boundaries. At the eastern boundary the mean sea level was applied as varying in time and along the line. Similarly, the mean sealevel variation from the tidal data was applied as boundary condition on the western boundary. Wind was applied as components in alongshore and cross-shore axes along with Sea level and atmospheric pressure are different entities. A similar soft start as SW, of 7200 seconds was applied to avoid sudden changes in the water level. The offshore conditions were transferred to the nearshore coastal area using the results of these simulations. The wave field was found to be dependent largely on the wind conditions applied over the domain. The wave heights were found to reach a maximum of $3.55 \mathrm{~m}$ with a period of 8.29 second. The wave height and directional distribution for one time step are shown in (Fig 5).

The output of wave radiation stresses from the SW simulations was used as input wave radiation stresses in the HD runs. The hydrodynamic simulations show the current and surface level variation for Zemmouri for August 2017. The current variation in the bay area is in the range of 0.1 to $0.5 \mathrm{~m} / \mathrm{s}$ in the eastern zone. Stronger currents in the range of 1 to $2.3 \mathrm{~m} / \mathrm{s}$ were predicted with the model at the western boundary. The currents inside the bay are in general much smaller than near the western boundary and near Cap Djinet Port. Currents reach an average value of $0.1 \mathrm{~m} / \mathrm{s}$ inside the bay with maximum values reaching $1.5 \mathrm{~m} / \mathrm{s}$. The current speed and directional distribution for one time step are shown in (Fig $6)$.

The results of these two configurations of SW \& HD were then used in the finer mesh as boundary conditions to arrive at results to check against the data available. The sediment transport table was then generated to cover the wave, current, sediment and bed slope parameters obtained from the hydrodynamic results and bathymetry. The combine waves and current model was then run using the wave field generated from SW run for Zemmouri coast. 


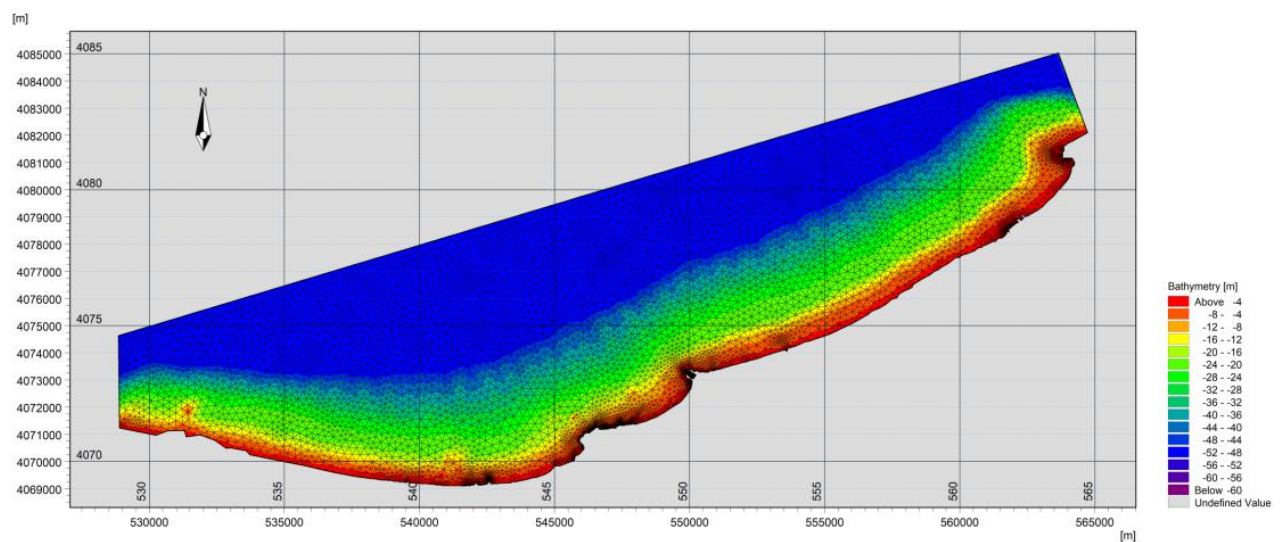

Fig. 4. The bathymetry of the examined area

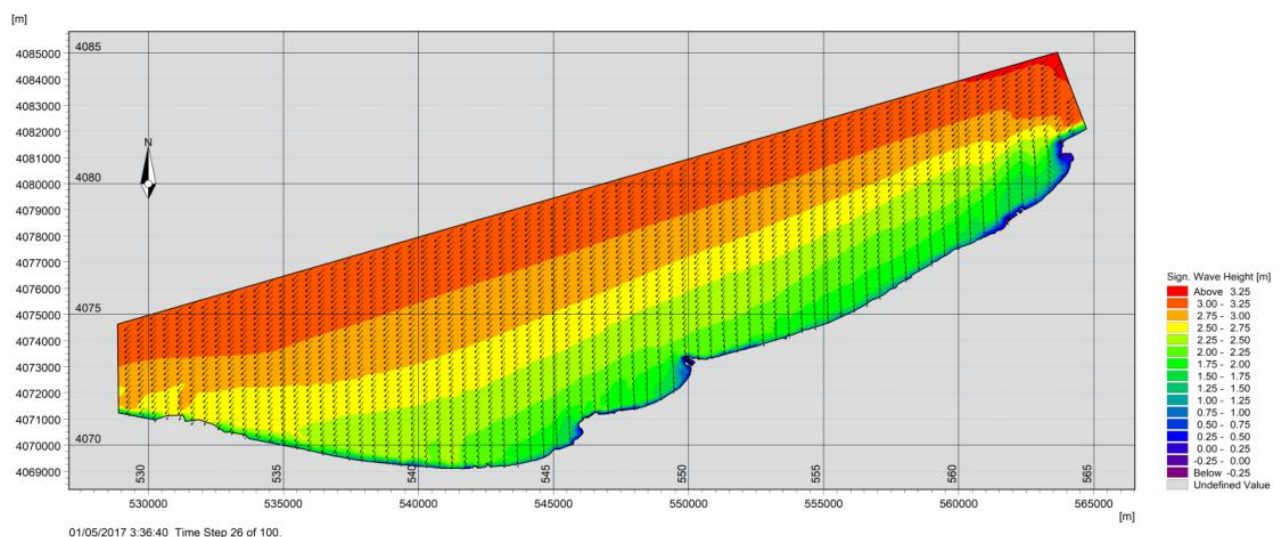

Fig. 5. Spatial distribution of significant wave height for the entire model domain

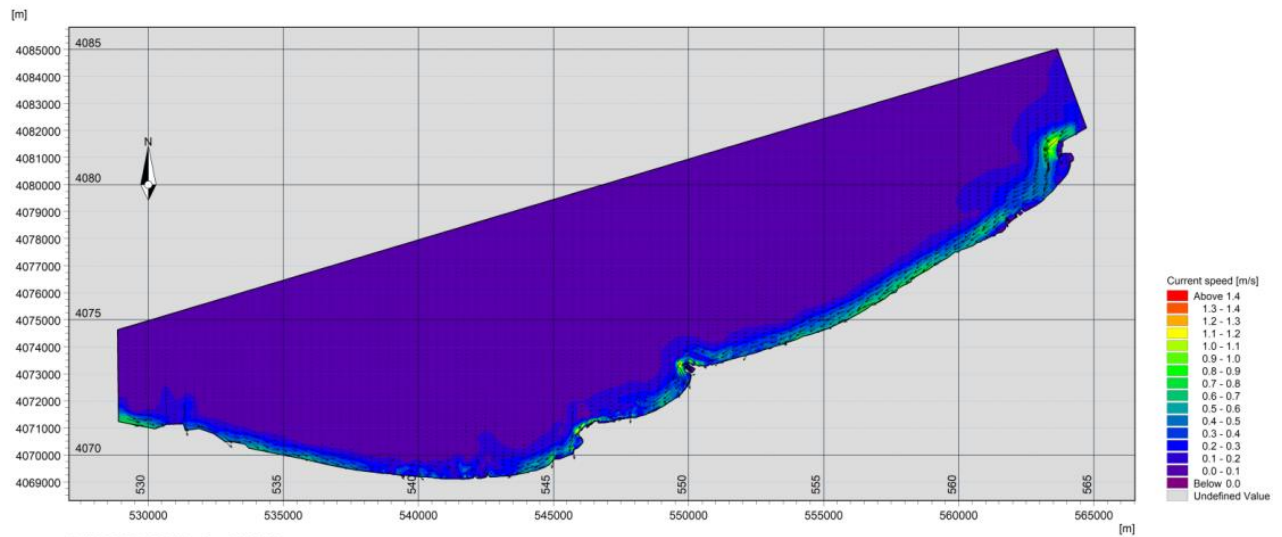

Fig. 6. Spatial distribution of current speed and direction for the entire model domain 


\section{sciendo}

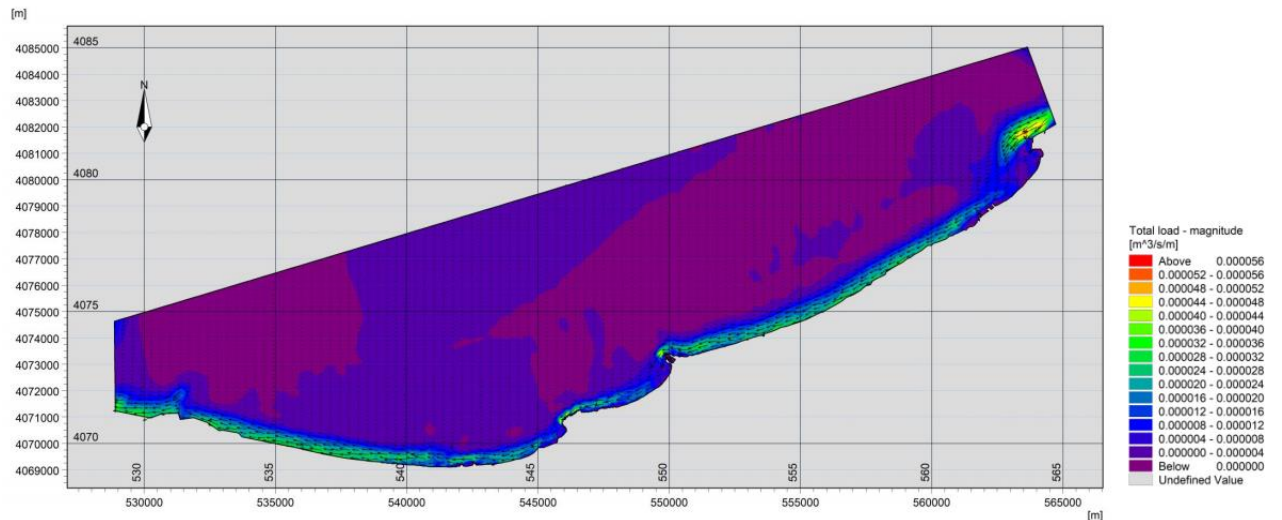

Fig. 7. Spatial distribution of total magnitude of sediment transport

The total load of sand transport is presented, along with the corresponding direction, for the examined extreme event. The highest values of sand transport (up to $-1120 \mathrm{~m}^{3} /$ year $/ \mathrm{m}$ ) are depicted mainly at the $-2 \mathrm{~m}$ isobath at the central and eastern side of the Zemmouri Bay (Zemmouri plage, Boumerdes, Ain taya), denoting erosion trend at a larger spatial scale compared to the west side. In the western part of the beach, at a zone of $80 \mathrm{~m}$ width from the coastline, accretion patterns are encountered, the sand transport is depicted near port jetty and groin $\left(+810 \mathrm{~m}^{3} /\right.$ year $\left./ \mathrm{m}\right)$.

\subsection{Shoreline analysis}

The changes of the coastline provide information on coastal dynamics and sedimentary transfers taking place along the coast.

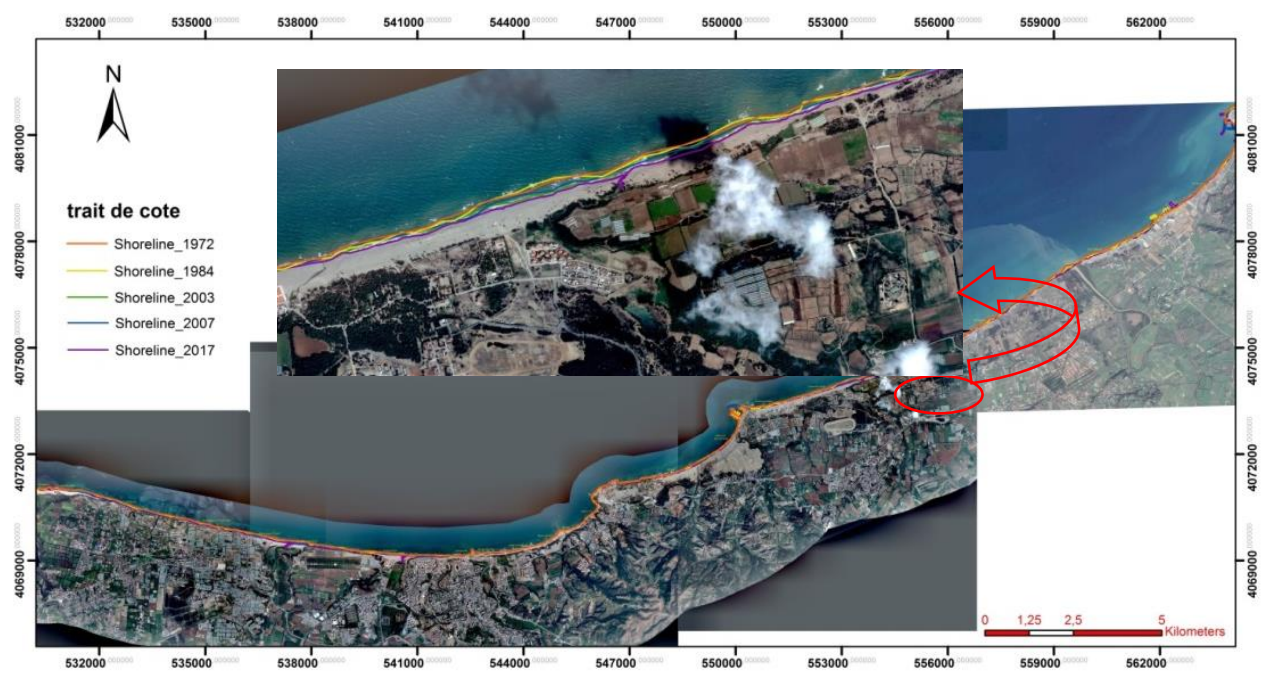

Fig.8. Shoreline map at different periods in the Zemmouri Bay from 1972 to 2017 


\section{sciendo}

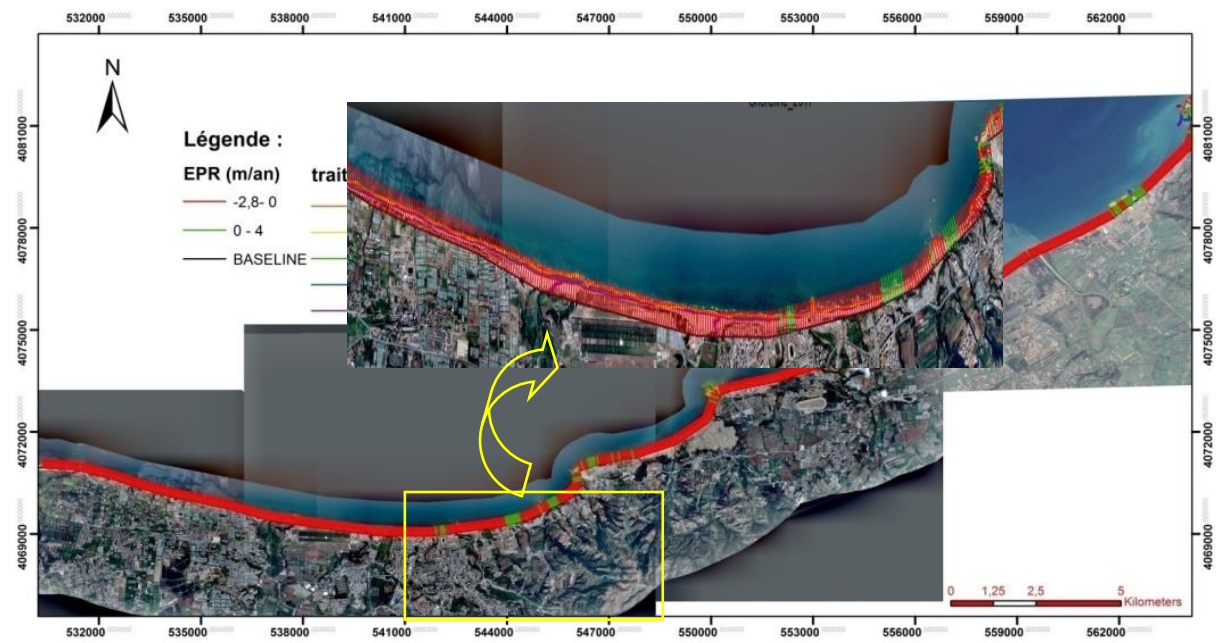

Fig.9. Transect map and the position of the shoreline in the Zemmouri Bay 1972 to 2017

Changes in the shoreline were estimated by applying the EPR method through the use of the DSAS tools. The EPR method divides the total coastal change distance by the time difference. This method performs its calculations using shorelines from two different dates. If there are more than two shorelines, calculations are performed for different combinations via the EPR method. First, a baseline is required to perform analyses using DSAS extension. Thus, a baseline that was parallel to the shoreline with a length of $54 \mathrm{~km}$ was created. A total of 900 transects was created at 50m intervals on this baseline (Fig 9).

The analytical results of changes of the shoreline position during these last 45 years (1972-2017) revealed that all transects of the study area (East, central and West) were subjected to recession. The average net rate of change calculated from EPR (the End Point Rate) methods, is 0.499, (Fig 10).

The results show a position of the shoreline which varies between the retreat phase and other in advanced according to the sectors; the stable sectors are observed in the rocky cliffs in the eastern zone. The most important retreat during this period was recorded in the western of the bay (Ain Taya, Boumerdes, figuier, Zemmouri,..), which reaches $-2.5 \mathrm{~m} /$ year. In the central part of the bay, the shoreline retreat reaches $-1.8 \mathrm{~m} /$ year, while the sectors in accretion mark a net rate of evolution of $1.5 \mathrm{~m} /$ year. The most significant progress is observed from the shore on the eastern part of the bay near the port of Cap Djinet, notably, and the accretion rate reaches $2 \mathrm{~m} / \mathrm{year}$; this event indicates a total positive balance. The general tendency of the entire coastline of the bay reveals that, during the 45 years (1972-2017), $80 \%$ of the shoreline has been eroded, against $20 \%$ in enlargement. 


\section{sciendo}

14 Ovidius University Annals Series: Civil Engineering, Year 21, 2019

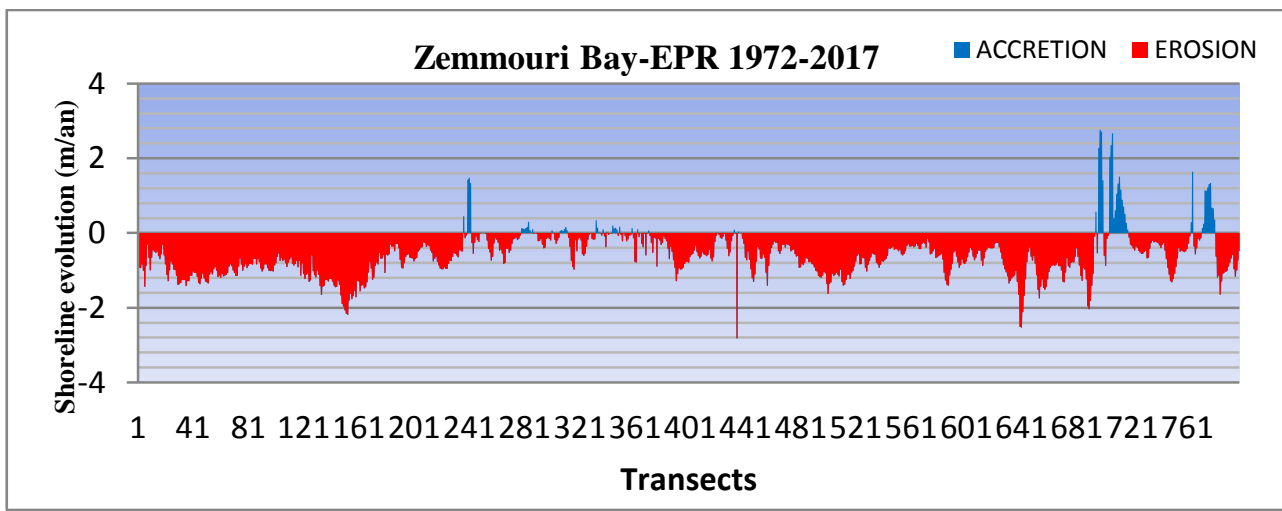

Fig.10. Global evolution of the coast of Zemmouri Bay (end point rate (EPR)), between 1972 and 2017

\section{CONCLUSIONS}

For calculating the hydrodynamics at the Zemmouri coast, MIKE21 Flow Module FM was used in which the MIKE21 Hydrodynamics was applied in combination with the MIKE21 Sediment Transport Module to simulate conditions where the sediment morphology includes feedback on the calculation of hydrodynamic and subsequent sediment transport conditions. The wave heights arriving at the bay have an average value of $1.2 \mathrm{~m}$ with a maximum of $2 \mathrm{~m}$ and an average peak period of $6 \mathrm{~s}$. Hydrodynamic simulations indicate that the current speed varies in the range of 0.01 to $0.6 \mathrm{~m} / \mathrm{s}$ but has a low average value of $0.15 \mathrm{~m} / \mathrm{s}$. The coastline kinematics study in the coast of Zemmouri has shown a regressive evolution of the shoreline. Indeed, this study puts in evidence large sectors in particular evolutions.

The spatial and temporal evolution of the Zemmouri coastline is not homogeneous; the obtained results of the period 1972- 2017 confirm it. This study showed that the coast experienced rapid erosion after 1973 due to construction of Zemmouri and Djinet ports. The proposed method in this part includes several shortcuts that can be improved with knowledge and quantification of coastal morphodynamic behavior. At this point, however, our approach allows at least managers to propose a retreat line, allowing them to anticipate the shore erosion phenomena, and could be used to ensure efficient management. Special control of these sectors during the future missions is necessary, in order to propose some actions as part of an integrated management approach to the Zemmouri coast.

\section{REFERENCES}

[1] Fenster MS, Dolan R (1994), Large-scale reversals in shoreline trends along the U.S. midAtlantic coast. Geology 22:543-546

[2] Liu, S., Fraser, C.S., Zhang, C., Ravanbakhsh, M., Tong, X. (2011), Georeferencing performance of THEOS satellite imagery. Photogramm. Rec. 26 (134), 250e262.

[3] Manca, E., Pascucci, V., Deluca, M., Cossu, A., Andreucci, S. (2013), Shoreline evolution related to coastal development of a managed beach in Alghero, Sardinia, Italy. Ocean. Coast. Manag. 85, 65e 76.

[4] Moore, L .( 2000), Shoreline mapping techniques. J. Coast. Res. 16, 111e124. 
[5] Shoshany, M., Degani, A. ( 1992), Shoreline detection by digital image processing of aerial photography. J. Coast. Res. 8 (1), 29e34

\section{Note:}

Romeo Ciortan - Ovidius University of Constanta, Bd. Mamaia nr. 124, 900356-Constanta, Romania (corresponding author to provide phone: +40-744 300 053; e-mail: ciortanromeo@ yahoo.com.

Khoudir Mezouar - National Higher School of Marine Sciences and Coastal Management (ENSSMAL). Campus Universitaire de Dely Ibrahim Bois des Cars, B.P. 19, 16320, Alger, Algérie;

e-mail:mezouarkhoudir@yahoo.fr 